\title{
Assoreamento dA Foz dos Rios
}

\author{
M. Filomena Camões*
}

\begin{abstract}
"... quando olhei atentamente para a zona da foz, deparei-me com uma situação um tanto ou quanto estranha: mesmo no sítio onde as águas do rio Âncora se juntam ao imenso mar, havia-se formado um pequeno monte de areia..."
\end{abstract}

http://vpamanha.blogs.sapo.pt/8947.html, 2007-11-19

Situações análogas à que é reportada na citação acima, podem ser encontradas em abundância. Nomeadamente, no estuário do rio Tejo, temos visto navios que encalham ao entrar no rio, quando em viagem anterior o canal de entrada estava desobstruído e, entretanto, terá ficado inesperadamente assoreado. Há mais de trinta anos, o caso do navio Tollan fez história; ao fim de três anos após ter encaIhado em frente ao Terreiro do Paço, quando fazia já parte da paisagem de Lisboa, o Tollan acabou por se afundar, Figura 1.

Exemplo mais recente é o da Marina do Parque das Nações, em Lisboa, construída aquando da Expo 1998 e cujo constante assoreamento obrigou a dragagens frequentes, e à sua inviabilização seguida de demorado processo de recuperação:

- “...As conclusões do estudo efectuado pela Marina do Parque das Nações apontam para um assoreamento caracterizado fundamentalmente por elevados índices (98\%) de materiais silto-argilosos de dimensões muito pequenas $(0.03 \mathrm{~mm})$ facilmente electrizáveis devido à salinidade, o que contribui para a sua aglomeração e precipitação. Não nos podemos esquecer que estamos a trabalhar na zona mais larga do estuário onde a velocidade das correntes diminui significativamente fora dos canais de navegação, e onde, necessariamente, a probabilidade das partículas atingirem a velocidade de corte que conduz à sua precipitação é mais elevada ... http://www.anmpn.pt 2008-12-09".

fcamoes@fc.ul.pt

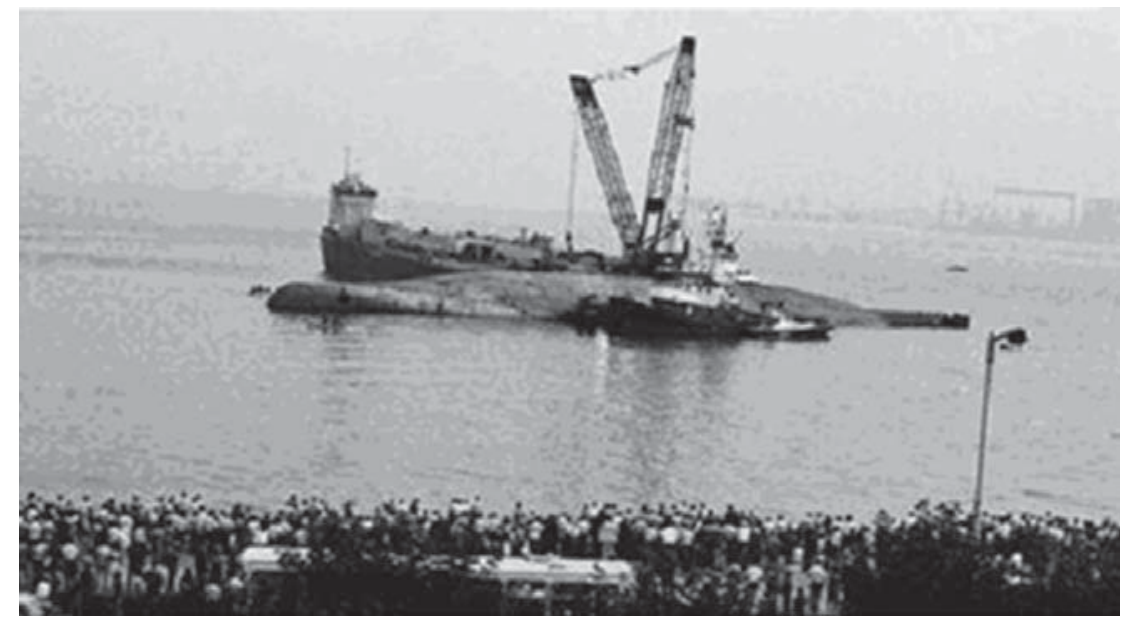

Figura 1 - O navio Tollan encalhou já lá vão 30 anos (http://www.ionline.pt, 16 de Fevereiro de 2010)

- "Após sete longos anos de encerramento, a Marina do Parque vai, finalmente, reabrir, restabelecendo assim a Saída para o Mar da Expo dos Oceanos. ... Os mecanismos de controlo de assoreamento (dique, comportas e anteporto) introduzidos nesta solução, serão com certeza uma referência para outros locais do Grande Estuário do Tejo, afectados também por índices elevados de assoreamento. ... http://www.amcpn.com 2009-07-26"

- "Depois de restabelecida a operacionalidade da Marina a 15 de Agosto,...http://www.anmpn.pt/informacoes 2009-10-03“

A explicação, ou melhor uma delas, aliás patente na primeira das três transcrições acima, é simples e os alunos de Química aprendem-na, quando em disciplinas introdutórias de Química Analítica estudam formas de lidar com algumas situações laboratoriais, envolvendo reacções de precipitação e optimização dos respectivos procedimentos.
Sob o ponto de vista termodinâmico, a formação de precipitados ocorre quando se atingem concentrações iónicas concordantes com o produto de solubilidade da correspondente substância pouco solúvel. No entanto, os mecanismos de precipitação diferem de composto para composto e aspectos cinéticos condicionam a precipitação, sendo, de uma forma geral, necessário passar por situações metaestáveis de sobressaturação antes que o precipitado se comece a formar, atingindo-se então o equilíbrio de solubilidade. Exemplos de casos bastante estudados, representando situações extremas, são o da precipitação de cloreto de prata, $\mathrm{AgCl}$, em que o precipitado se começa a formar quando se atingem concentrações de iões $\mathrm{Cl}_{(\text {aq) }}$ e $\mathrm{Ag}^{+}{ }_{(\mathrm{aq})}$ duplas do valor da solubilidade do composto em água, e o da precipitação de sulfato de bário, $\mathrm{BaSO}_{4}$, em que a concentração de sulfato terá que ser superior a 160 vezes o valor da solubilidade do sal, antes que a precipitação se inicie. A precipitação espontânea inicia-se pela 
formação de agrupamentos de iões seguida da de núcleos, antes que se formem partículas macroscópicas. No caso do cloreto de prata a nucleação em solução sobressaturada é rápida, mas no caso do sulfato de bário há um considerável tempo de indução, demorando algum tempo desde que se adicionam os reagentes até que se torna evidente a formação do precipitado; aqui, sendo a solução extremamente sobressaturada, a precipitação uma vez iniciada acontece muito rapidamente, logo com formação de precipitado de partículas muito pequenas (5 x 10-5 a $10^{-7} \mathrm{~cm}$ ), de difícil filtração ou centrifugação, constituindo-se em suspensão coloidal. A nucleação pode ser induzida por agitação forte, pela presença de impurezas que sirvam de núcleos de precipitação ou por adição de cristais de outras substâncias. Quando dois eléctrodos são colocados numa suspensão coloidal e entre eles se aplica uma corrente, as partículas coloidais movem-se para os eléctrodos, o que prova que têm carga. Esta provém da adsorção preferencial, selectiva, de iões da solução à sua superfície formando uma camada eléctrica de um dado sinal, função dos iões adsorvidos, que por sua vez, promovem a atracção electrostática de iões de carga oposta, formando-se assim uma contra-camada difusa que define a carga positiva ou negativa das partículas do colóide, ou micelas; geralmente os sólidos suspensos têm uma carga negativa, Figura 2.

Todas as partículas têm a mesma carga, logo repelem-se e o colóide adquire estabilidade, permanecendo em supensão. A repulsão pode ser contrariada por aquecimento, que

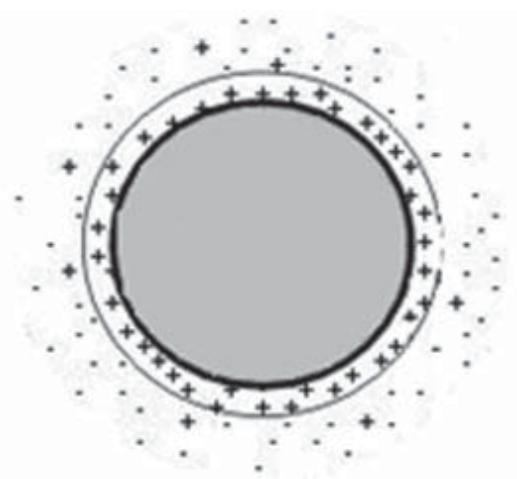

Figura 2 - Representação esquemática de uma micela, com núcleo neutro e dupla camada confere maior energia cinética às partículas, acelerando-as, podendo desta forma ser ultrapassada a repulsão, que também pode ser diminuída contraindo a espessura da dupla camada eléctrica que envolve o núcleo neutro. Isto consegue-se por adição de electrólitos, sendo mais eficaz pela adição de polielectrólitos com iões de elevada densidade de carga oposta à da camada externa das partículas. As partículas agregam-se, mas não de uma forma estável, isto é, não precipitam, floculam; pelo facto de continuarem a ser carregadas, caso se alterem as condições que favoreceram a floculação, por exemplo por execução de operação de lavagem do depósito, ocorre a peptização, reconstituindo-se a suspensão coloidal.

É esta a base do processo de coagulação e floculação de colóides que conferem turvação a águas naturais e residuais e que é usado no tratamento da água para abastecimento, pelo procedimento generalizado de adição de sulfato de alumínio, $\mathrm{Al}_{2}\left(\mathrm{SO}_{4}\right)_{3} \cdot 18 \mathrm{H}_{2} \mathrm{O}$. Tal tem, como consequência, a ocorrência, nas águas tratadas, de concentrações vestigiais de ião alumínio, $\mathrm{Al}^{3+}{ }_{(\text {aq) }}$ que, em princípio, não constitui perigo para a saúde dos indivíduos saudáveis que as ingiram através da função digestiva. No entanto, em termos de saúde pública, a alimentação não é o fim mais exigente e a utilização da água para fins terapêuticos, como é o caso da hemodiálise, requer mais elevado grau de pureza, nomeadamente no que se refere a $\mathrm{Al}^{3+}{ }_{(a q)}$, $\mathrm{O}$ que pode ser conseguido com grande eficácia fazendo passar a água por resinas de permuta-iónica.

A fundamentação que, em termos gerais, acima se apresenta para o fenómeno da coagulação/floculação, é a mesma que contribui para explicar o assoreamento da foz dos rios, quando águas doces fluviais, que são suspensões coloidais, são transportadas para o mar e encontram a água salgada, meio electrolítico de concentração relativamente elevada (Força iónica $\approx$ $0.7 \mathrm{M})$.

A garantia das condições de navegabilidade exige a remoção dos depósitos, ou seja a dragagem. Os processos de dragagem podem ter diferente finalidade e vão desde a "dragagem inicial", com a retirada de material virgem, para formação de um canal artificial, passando pelas "dragagens de manutenção" para a retirada de material sedimentar depositado recentemente, com a finalidade de manter a profundidade do canal propiciando principalmente a movimentação de embarcações de vários tamanhos em portos e marinas, até à "dragagem ambiental".

A dragagem ambiental é um processo que, para além de visar a reposição de acessos de meios de transporte, visa também a circulação de águas e biota para garantia da qualidade ambiental, tendo como objectivo máximo a remoção de sedimentos contaminados por compostos orgânicos e inorgânicos, que tendem a incorporar em elevada variedade e quantidade. Existem procedimentos rigorosos aplicados tanto à operação de dragagem, como ao transporte e manuseamento destes materiais. Uma draga hidráulica, especialmente adaptada com tubos de ligação entre os fundos e a superfície, pode retirar sedimentos finos onde a adsorção de contaminantes é extrema, evitando ressuspensão, minimizando a sua dispersão para áreas adjacentes ao sítio de dragagem, evitando repetição de catástrofes ecológicas do passado. Uma dessas catástrofes e que se constituiu em caso de estudo, não só pela dimensão do seu impacto na saúde de milhares de indivíduos, mas sobretudo pelo que ele revela sobre a importância da compreensão dos ciclos biogeoquímicos, na correcta abordagem de questões de desenvolvimento sustentável, é o da Baía de Minamata, nas margens do Mar Yatsushiro, no Japão, onde, em 1956 foi reportado um doente com sintomas nervosos de causa desconhecida. Posteriormente, em 1965, mais a norte, na cidade costeira de Niigata junto ao rio Agano, foram registados outros pacientes com doença semelhante, tendo-lhes sido diagnosticada encefalite por intoxicação química. Tendo sido patente a incidência em homens e mulheres, com exclusão de crianças, e em gatos de familiares das vítimas, as deconfianças da origem da doença centraram-se em peixes e marisco. Dada a etiologia peculiar da doença 
e o escasso conhecimento científico, à época, tanto a nível da transmissão do mercúrio ao longo da cadeia alimentar, como relativamente à especiação química do mercúrio e aos métodos de análise para quantidades vestigiais, o mercúrio usado na fábrica Chisso como catalisador do fabrico de acetaldeído, formando também como sub-produto, metilmercúrio, $\left[\mathrm{CH}_{3} \mathrm{Hg}\right]^{+}$, de elevada estabilidade $(\mathrm{K}=1.8-2.1)$ e a mais tóxica espécie química com mercúrio, tal como é reconhecida pela Organização Mundial de Saúde, só se tornou suspeito passado mais três anos. As primeiras análises, de natureza puramente química, começaram por pesquisar, no meio aquático, a formação do sal de mercúrio altamente insolúvel, sulfureto de mercúrio, $\mathrm{HgS}$ $\left(\mathrm{Ks}=1.0 \times 10^{-52}\right)$, tendo, com surpresa, os testes efectuados sido negativos. Além de origem antropogénica, o mercúrio pode ter proveniência natu- ral, da crosta terrestre, e ser metilado por bactérias sulfatorredutoras, sendo a taxa de metilação maior na camada superficial dos sedimentos.

Actualmente o mercúrio total é correntemente avaliado por espectroscopia de absorção atómica, AAS, com chama e o metilmercúrio (uma das formas de mercúrio orgânico passíveis de se formarem por complexação de mercúrio por matéria orgânica biológica) por cromatografia gasosa com detecção por captura electrónica, ECD. Decorridos 12 anos, em que a descarga de mercúrio foi estimada em mais de 70 toneladas, em 1968, o Governo Americano compilou toda a informação sobre a "doença de Minamata" e emitiu o seguinte comunicado "Minamata disease is a poisoning disease of the central nervous system caused by methylmercury compound which was produced as a by-product in the process of manufacturing acetaldehyde at the Chisso Co. Ltd. In Minamata City and Showas Senko Co. Ltd., located upstream at Agano River".

Entretanto, os efeitos tinham-se tornado também evidentes em crianças, provenientes da exposição fetal a metilmercúrio através da placenta, ou devido a ingestão oral de metilmercúrio após o nascimento. Neste período foi reconhecido que mais de 900 pessoas morreram da doença, 2955 terão sofrido da mesma, das quais 2265 viveram na costa do Mar Yatsushiro. A bioacumulação de mercúrio ao longo da cadeia alimentar atinge um factor multiplicativo da ordem de 1 milhão e, mesmo cessando as fontes poluidoras de mercúrio, este mantém-se activo para metilação durante 100 anos. Um estudo de 2001 estima que cerca de 2 milhões de pessoas podem ter sido afectadas.

\section{Actualidades Científicas}

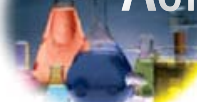

\section{Fulerenos no Espaço!}

Foram detectadas grandes quantidades de fulerenos $\mathrm{C}_{60}$ e $\mathrm{C}_{70}$ numa explosão de gás ocorrida numa estrela moribunda, a primeira descoberta inequívoca desta forma de carbono no espaço.

Esta revelação sugere que os fulerenos podem formar-se rapidamente no espaço, se houver condições propícias para tal.

Desde há muito que se acredita que os fulerenos, estáveis e inertes, podem existir no espaço, particularmente próximos do ambiente de estrelas ricas em carbono, mas a sua evidência estava limitada a espectros inconclusivos e a vestígios das moléculas em meteoritos que caíram na Terra.

Agora, o astrónomo Jan Cami da Universidade de Western Ontario e os seus colegas, apontaram o telescópio da NASA Spitzer Space a uma nebulosa planetária rica em carbono, uma estrela nos estágios finais de vida, e encontraram todas as linhas espectrais características da emissão de infra-vermelho dos fulerenos $\mathrm{C}_{60}$ e $\mathrm{C}_{70}$ (Science, DOI: 10.1126/science.1192035).

Pascale Ehrenfreund, professor de astrobiologia da Universidade de Amesterdão, realça que a detecção é muito clara e que este novos dados são o melhor que viu até à data.

As gigantescas massas de gás projectadas pelas nebulosas planetárias são fontes ricas em grandes moléculas, formadas por reacções químicas entre elementos. Muitos são elementos pesados, como o carbono, que as estrelas sintetizaram durante a sua vida.

Estas espécies vão depois povoar o espaço interestelar. "A detecção de fulerenos e a identificação do seu local de formação são consideradas prioridades no campo da química orgânica interestelar", escreveram os autores no artigo publicado na Science.

Tentativas prévias para encontrar fulerenos em nebulosas planetárias encontraram dificuldades, uma vez que as emissões destas estrelas são por vezes dominadas pelas emissões fortes e complexas de uma outra classe de moléculas ricas em carbono, os hidrocarbonetos policíclicos aromáticos. Mas, na nebulosa planetária estudada por estes autores não havia sinais de hidrocarbonetos policíclicos aromáticos, indicando que o ambiente desta estrela moribunda é particularmente pobre em hidrogénio, uma condição ideal para a formação de fulerenos.

(Adaptado de Chemical \& Engineering News 2010, 88, 8) 
Top Chemistry

Global

Visibility
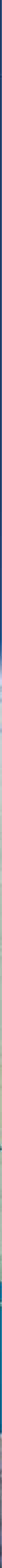